\title{
Possible Protective Effect of Propolis on Cardiac Muscle Injury Induced by Liver Fibrosis in Adult Male Albino Rat: Histological Study
}

Original Article
Reda H. El Bakary and Mona Tayssir Sadek

Histology and Cell Biology Department, Faculty of Medicine, Tanta University

\begin{abstract}
Introduction: Most chronic liver diseases lead to cirrhotic cardiomyopathy that occurs as a late complication in $56 \%$ of the hepatic patients. Propolis is considered as a tonic that increases the body resistance to aging. It also decreases the risk of cardiovascular diseases and atherosclerosis.

Aim of the work: was to study the possible protective role of propolis on the histological changes occurred in cardiac muscle secondary to liver fibrosis.

Materials and Methods: 40 healthy male albino rats were randomly divided into 4groups including: control group (group I), propolis treated group (group II) given $20 \mathrm{mg}$ propolis once daily orally for 4 weeks, (group III) received $0.2 \mathrm{ml} / 100 \mathrm{gm}$ carbon tetrachloride by subcutaneous injection for 4 weeks and (group IV) received both carbon tetrachloride and propolis at the same dose of group IIand III for the same period. At the end of the experiment, all the rats were sacrificed, and cardiac muscle was obtained and processed for light and electron microscopic examination.

Results: Group III revealed widely separated cardiomyocytes with excessive connective tissue nuclei between them. Cytoplasmic vacuolations and marked fibrillolysis were observed. Cellular infiltration and dilated blood vessels were found. Excessive collagen fibers were detected by Mallory stain. Ultrastructural changes included irregular sarcomeres, interrupted intercalated disks, degenerated mitochondria and dilated sarcoplasmic reticulum. Group IV showed partial improvement with regular arrangement of cardiac fibers and sarcomeres.

Conclusions: Use of propolis partially improved the histological changes that occurred in the cardiac muscle as a result of liver fibrosis.
\end{abstract}

Received: 01 June 2018, Accepted: 11 September 2018

Key Words: Cardiac muscle, liver fibrosis, propolis, rat.

Corresponding Author: Reda Hassan Elbakary, M.D, Histology Department, Faculty of Medicine, Tanta University, Egypt, Tel.: +2 04 03600256, E-mail: redahassan99@gmail.com

ISSN: $1110-0559$, Vol. 41 , No. 4

\section{INTRODUCTION}

Cirrhotic cardiomyopathy $(\mathrm{CCM})$ is a heart disease characterized by chronic changes in the structure and function of the cardiac muscle. It occurs in patients suffering from liver cirrhosis with no previous cardiac diseases ${ }^{[1]}$. Liver fibrosis is a common end result of most chronic liver diseases $^{[2]}$. It is considered a wound healing like process in which there is excessive deposition of the extracellular matrix of the connective tissue. This process occurs over many years and finally results in hepatic cirrhosis, failure and even carcinoma ${ }^{[3]}$.

Patients with cirrhosis develop a progressive impairment in their circulatory and cardiac function. Most common manifestations in cirrhotic cardiomyopathy are increased baseline cardiac output, abnormal systolic and diastolic function as well as disturbed electrical response of the cardiac muscle with prolonged Q-T interval ${ }^{[4]}$.

Carbon tetrachloride (CCL4) is one of the hydrocarbons that have been introduced into industry as a solvent, fire extinguisher and dry cleaning agent ${ }^{[5]}$. It is a widely used model in induction of liver fibrosis ${ }^{[6]}$. Chronic CCL4 administration results in a condition of oxidative stress that leads to induction and progression of liver fibrosis. Therefore, treatment with antioxidants may be effective in prevention or regression of the liver fibrosis ${ }^{[7]}$.

Propolis (bee glue) is a product synthesized by the bees from multiple different plants. It consists of resins, polyphenols, flavonoids, fatty acids, essential oils, wax, pollen, organic substances and minerals. In addition, it contains various vitamins (B complex, $\mathrm{C}$ and $\mathrm{E}$ ), many minerals $(\mathrm{Zn}, \mathrm{Mg}, \mathrm{Cu}, \mathrm{Fe}, \mathrm{Mn}, \mathrm{Ni}$ and $\mathrm{Ca}$ ) and some other trace elements. Due to its content of flavonoids and phenolic acids, propolis has antioxidant, anti-inflammatory, antibacterial, antiviral, immunomodulatory and antiproliferative properties ${ }^{[8]}$. Propolis is also considered as a tonic, an antiseptic substance and a natural antibiotic. It naturally strengthens the body immunity and increase 
the body resistance to aging, heart and liver diseases and also cancer of the skin, stomach and intestine ${ }^{[9]}$. Moreover, it decreases the risk of cardiovascular diseases and atherosclerosis ${ }^{[10]}$.

Liver diseases are very common problem in Egypt and its effect on the heart is inevitable result. So, it is very important to search for a protective substance that may minimize the damaging effect of liver fibrosis on the heart. From these data aim of this work was to study the possible protective role of simultaneous administration of propolis on the histological changes in the cardiac muscle caused by liver fibrosis.

\section{MATERIALS AND METHODS:}

\section{Drugs and chemicals:}

Carbon tetrachloride (CCL4) was obtained from Inter Trade CO., Cairo, Egypt in a solution form. CCL4 was diluted in a ratio of $1: 1$ of olive oil. It used in a dose of $0.2 \mathrm{ml} / 100 \mathrm{~g} \mathrm{CCl} 4$ in olive oil by subcutaneous injection ${ }^{[11]}$. Propolis was obtained in the form of capsules (400 mg) produced by Sigma Pharmaceutical Industries for International Business Establishment Company (IBE Pharma). Each capsule was dissolved in $20 \mathrm{ml}$ distilled water, so each $1 \mathrm{ml}$ of the resulting solution contained $20 \mathrm{mg}$ of propolis powder which is equal to 100 $\mathrm{mg} / \mathrm{kg}$ per day ${ }^{[12]}$.

\section{Animals}

This study was carried out on 40 adult male albino rats, weighing 180-200 gm each. The rats were housed in clean properly ventilated cages under similar conditions, acclimatized to their environment one week before starting the experiment and allowed free access to water and food throughout the period of the experiment.

\section{Experimental design:}

\section{The rats were randomly divided into 4 groups:}

Group (I): included 10 rats divided into subgroup Aand subgroup B(5rats each). Subgroup A received no treatment and served as negative control group. Subgroup B received $0.2 \mathrm{ml} / 100 \mathrm{gm}$ of olive oil once daily subcutaneously for 4 weeks and served as positive control group.

Group (II): included 10 rats that received $1 \mathrm{ml}$ of propolis solution $(20 \mathrm{mg})$ once daily orally for 4 weeks.

Group (III): included 10 rats. The animals of this group received subcutaneous injection of carbon tetrachloride once daily in a dose of $0.2 \mathrm{ml} / 100 \mathrm{gm}$ diluted in olive oil in a ratio of $1: 1$ for 4 weeks.

Group (IV): included 10 rats. The animals of this group received subcutaneous injection of carbon tetrachloride once daily in a dose of $0.2 \mathrm{ml} / 100$ gm diluted in olive oil in a ratio of $1: 1$ concomitant with $1 \mathrm{ml}$ of propolis solution once daily orally for 4 weeks.

At the end of the experiment period, the animals were sacrificed by cervical dislocation one day after the last dose and then the heart and the liver of each animal were dissected. Specimens from the left ventricle of the heart and the upper part of the right lobe of the liver were excised. The liver specimen and part of the left ventricle were fixed in $10 \%$ formol saline solution then processed to obtain paraffin sections of 5- $\mu \mathrm{m}$ thickness. The sections then were stained with HandE and Mallory trichrome and examined by the light microscope to ensure induction of liver fibrosis and to assess the degree of cardiac affection. The second part of the left ventricle was fixed in $2.5 \%$ phosphate buffered glutaraldehyde and processed for transmission electron microscopic examination to study the ultrastructural changes in the cardiac muscle ${ }^{[13]}$. The ultrathin sections were examined and photographed with JEM transmission electron microscope in EM unit, Faculty of Medicine, Tanta University. The experiment was approved by the Local Ethics Committee of the Faculty of Medicine, Tanta University.

\section{Morphometric analysis:}

Leica Qwin 500 C Image analyzer computer system (Leica Imaging System LTD., Cambridge, England) in (Central Research Lab, Tanta Faculty of Medicine) was used to obtain the morphometric data in this study. Ten non overlapping fields in slides of each animal of each group were examined to measure the mean area percentage (\%) of collagen fiber content (in Mallory's trichrome-stained sections). The total area was measured by adjusting the color threshold while excluding the background and then the blue stained area was selected and measured to calculate the area percentage (\%)by the following equation:

The mean area percentage $(\%)=$ (blue stained area/ total area)X100.

\section{Statistical analysis}

The values were represented as mean $\pm \mathrm{SD}$. The data were analyzed, calculated and compared between groups using SPSS software (Chicago, USA). Differences were regarded significant if $P$ value was less than 0.05 .

\section{RESULTS}

In the present work, no deaths occurred throughout the experimental period.

\section{Histological Results:}

Sections of liver from control group showing normal histological structure of the liver with central vein and hepatocytes around it. Also blood sinusoids were found in between hepatocytes. Few collagen fibers present around the central vein (Fig. 1). Liver specimens were examined from group three to ensure induction of liver fibrosis in the form of distortion of the normal liver architecture. This finding was confirmed by the Mallory stained sections which revealed excessive collagen fibers deposition around the central veins and portal areas as well as in between the hepatic lobules (Fig. 2). 


\section{Haematoxylin and eosin stains:}

Examination of samples obtained from the control group (group I) and propolis-treated group (group II) revealed no variation between them. The cardiac muscle fibers consisted of cylindrical cells with one or two, large, vesicular, oval, centrally located nuclei and acidophilic sarcoplasm. The cells showed branching and re-anatomizing with each other. The muscle fibers were separated by connective tissue endomesium containing blood vessels (Fig. 3).

Sections from group III (which received CCl4) showed abnormal arrangement of the cardiac muscle fibers which appeared widely separated from each other. Multiple fat cells and homogenous acidophilic substance were seen in between some cardiomyocytes. Sarcoplasmic vacuolations of variable size were also observed (Fig. 4).Some cardiac muscle fibers appeared thin while others were thickened. Some cardiomyocytes revealed loss of their striations while many other cells showed areas of discontinuation. Increased connective tissue nuclei between the cardiomyocytes were observed. These nuclei appeared thin dark and flattened on the surface of the cardiomyocytes. Mild cellular infiltration was also reported (Fig. 5). Other sections showed marked cellular infiltration with large dilated blood vessels and extravasated red blood cells between the cardiomyocytes(Fig. 6).As regards the nuclei, most of them appeared dark, irregular in shape and peripheral in position with pale area at one side of them (Fig. 7).

Sections of group IV (CCL4and propolis treated group) revealed improvement of the histological changes that were detected in group III. Generally, the muscle fibers restored their normal features, however, few muscle fibers appeared enlarged in size with deeply acidophilic cytoplasm while few others revealed areas of discontinuation. Little cellular infiltration and blood vessels dilatation were still observed in only few sections (Fig. 8). Most of the nuclei regained their normal central position and vesicular appearance, but few were still dark and peripheral (Fig. 9).

\section{Mallory's trichrome stained sections:}

Cardiac muscle sections from both control and propolis treated groups showed little collagen fibers between the cardiac muscle fibers (Fig. 10). Sections from the CCL4 treated group (group 3) revealed apparent increase in collagen fibers deposition, which appeared as wavy bundles in between the cardiac muscle fibers and at areas of discontinuation of the cardiomyocytes (Fig. 11).Sections from rats of group IV (CCL4and propolis treated group) revealed more or less apparently normal collagen fibers deposition except for few areas in few sections which still showed deposition of collagen fibers at areas of lost cardiomyocytes (Fig. 12).

Morphometric analysis of the mean area percentage of collagen fiber content in the CCL4-treated group (group III) (16.6 \pm 1.41$)$ revealed a significant increase $(p=0.013)$ compared to the control group $(7.06 \pm 0.74)$ while group IV $(10.54 \pm 1.08)$ showed significant decrease $(p=0.02)$ when compared to group III (Table1 and Histogram1).

\section{Electron microscopic results:}

Electron microscopic examination of the cardiac muscle sections obtained from control and propolistreated groups (groups I and II respectively) revealed the same ultrastructural features. The cardiomyocytes showed regular arrangement of the myofibrils in the form of alternating dark (A) and light (I) bands forming sarcomeres. Each sarcomere extended between two successive dark $\mathrm{Z}$ lines which bisected the (I) bands. The neighboring cardiomyocytes were connected end-to-end by intercalated disks with their specific step ladder pattern of distribution. Each cardiomyocyte showed a single nucleus with extended chromatin and apparent nucleolus. Numerous mitochondria were observed in rows in between the myofibrils (Fig. 13).

Electron microscopic examination of the cardiac muscle sections obtained from group III revealed disorganization of the normal structure of the cardiomyocytes. The sarcomeres were disrupted with focal lysis and fragmentation of the myofibrils. Irregular sarcolemma, cytoplasmic rarefaction and mitochondria with variable size and shape were observed. The myofibrils appeared variable in size; some were very thin while others were thick. Collagen fibers were also observed in between the cardiomyocytes (Fig. 14 and 15).

Partially damaged mitochondria, dilated sarcoplasmic reticulum and interrupted intercalated disk were also reported (Fig. 16). Some nuclei showed irregular outline with presence of indentations (Fig. 17).Congested blood capillaries and inflammatory cells were observed in between the cardiomyocytes (Fig. 18).

Electron microscopic examination of the cardiac muscle sections obtained from group IV showed partial improvement of the changes previously observed in the cardiomyocytes treated with CCL4in the form of regular arrangement of the sarcomeres and the myofibrils. Aggregation of the mitochondria under the sarcolemma and few sarcoplasmic vacuoles were detected. Some nuclei appeared irregular while others were small (Fig. 19).

Table 1: Morphometric analysis of the mean area percentage of collagen fiber content in the cardiac muscle. Data is expressed as mean \pm standard deviation. $* P<0.05$ indicates significance versus the control group. \# indicates significance versus group III.

\begin{tabular}{ccccc}
\hline $\begin{array}{c}\text { Control } \\
\text { group }\end{array}$ & Group II & Group III & Group IV & $\begin{array}{c}\text { Anova } P \\
\text { value }\end{array}$ \\
\hline $7.056 \pm 0.74$ & $7.22 \pm 0.19$ & $16.6 \pm 1.41^{*}$ & $10.54 \pm 1.08 \#$ & 0.007 \\
\hline
\end{tabular}




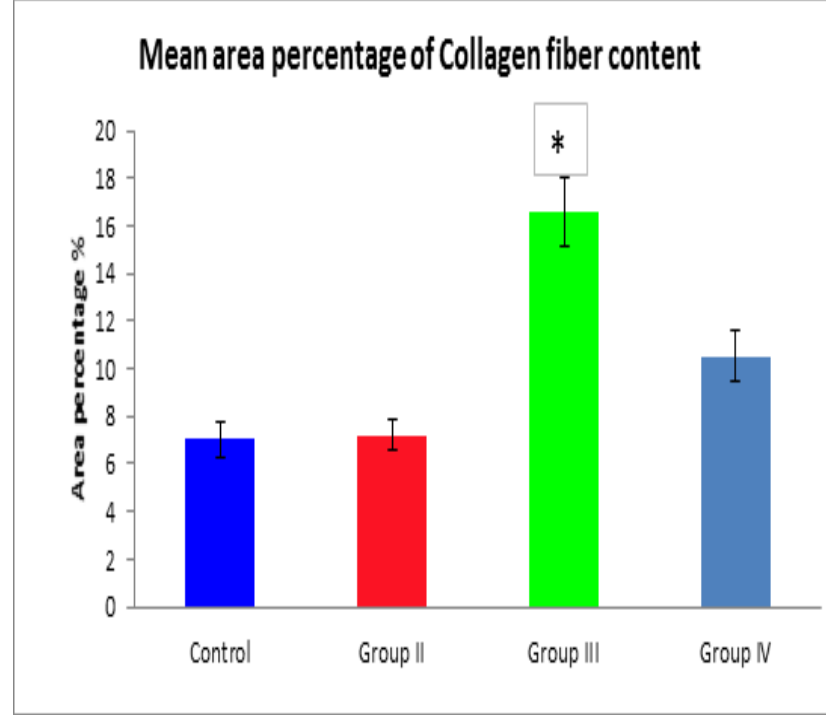

Histogram1: Mean area percentage (\%) of collagen fibers content in the cardiac muscle.

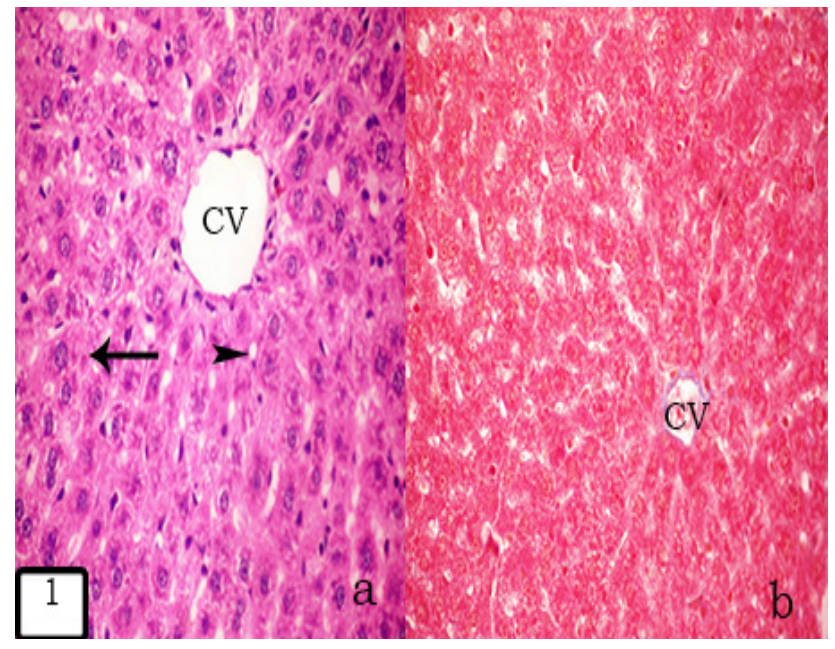

Fig 1: A photomicrograph of liver section of the control group showing (a) hepatocytes (arrow) arranged around the central vein (CV) and blood sinusoid (arrow head) in between. (b) Few collagen fibers around the central vein (CV) (a, HandE X 400 b, Mallory trichrome X400).

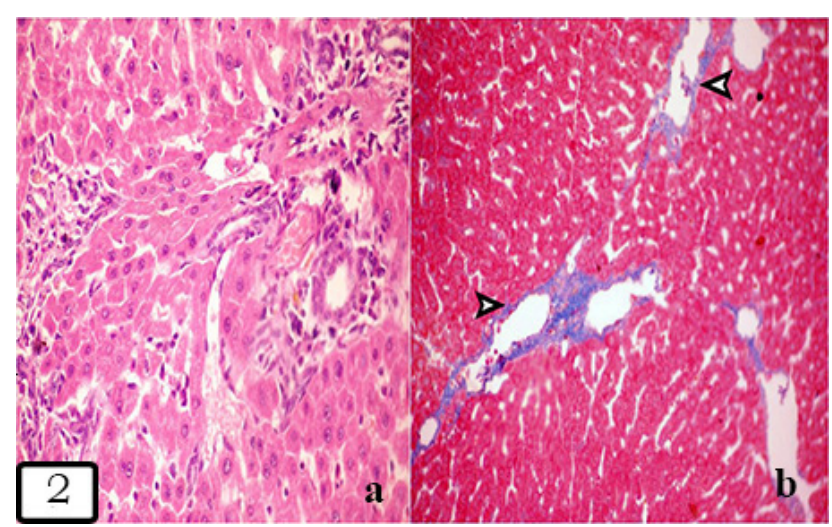

Fig 2: A photomicrograph of liver section of group III showing (a) irregularly arranged hepatocytes with loss of the normal architecture of hepatic lobule. (b) Excessive collagen fibers deposition (arrow head) (a, HandE X 400 b, Mallory trichrome X400).

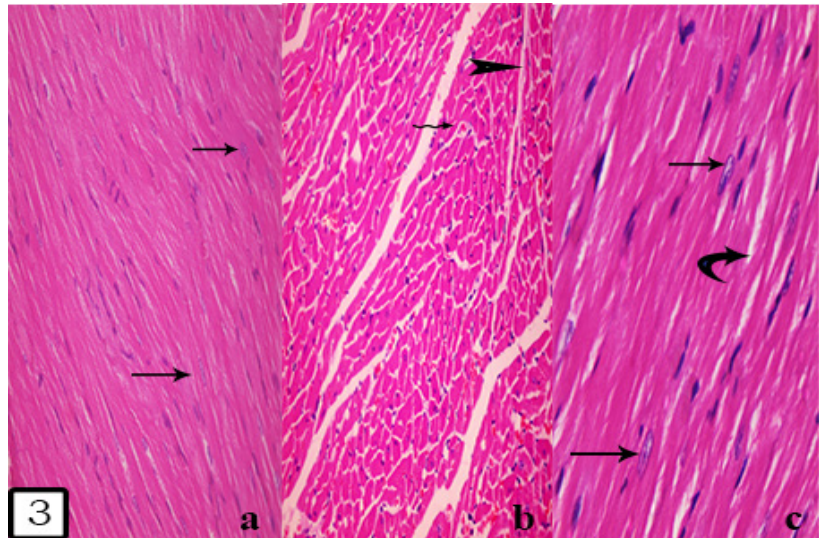

Fig 3: A photomicrograph of cardiac muscle of the control group showing branched cylindrical muscle fibers (curved arrow) (C) with acidophilic sarcoplasm and large, oval centrally located nuclei (arrow) (aandc). Connective tissue (arrow head) containing blood capillaries (zigzag arrow) were observed surrounding the muscle fibers (b) (HandE X a, b 400 and c 1000).

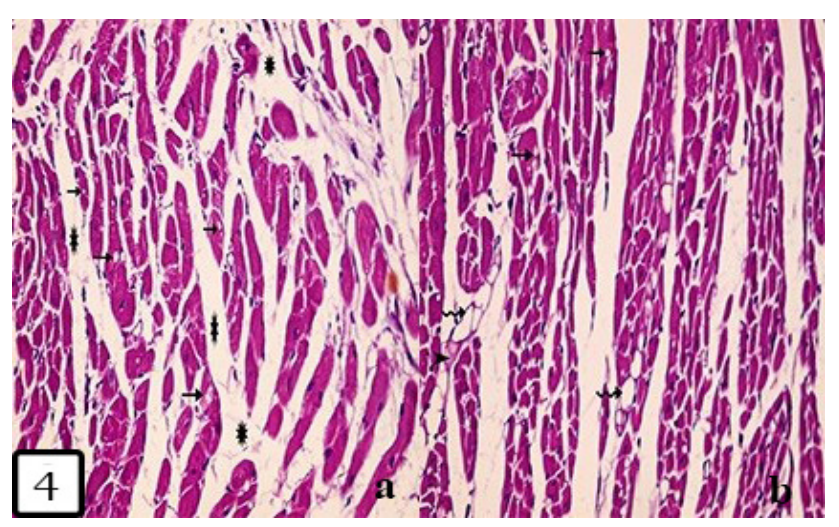

Fig 4: A photomicrograph of the cardiac muscle of group III showing (a)Wide spaces between the cardiomyocytes (star) and vacuoles in their sarcoplasm in (aandb) (arrows).(b)Homogenous acidophilic substance (arrow head) and fat cells (zigzag arrow) were found between the cardiomyocytes (HandE X400).

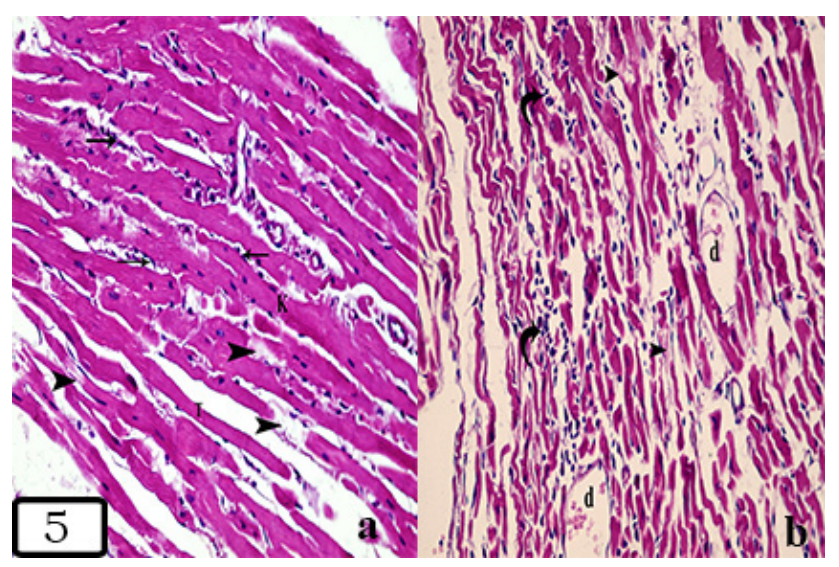

Fig 5: A photomicrograph of the cardiac muscle sections of group III showing (a)Loss of sarcoplasmic striations of the cardiomyocytes with areas of discontinuation in (aandb) (arrow head). CT nuclei (arrow) were observed on the outer surface of the cardiomyocytes. Variable size of the muscle fibers were observed either thick $(\mathrm{K})$ or thin $(\mathrm{T})$. (b) Cellular infiltrations (curved arrow) and dilated blood vessels (d)(HandE X400). 


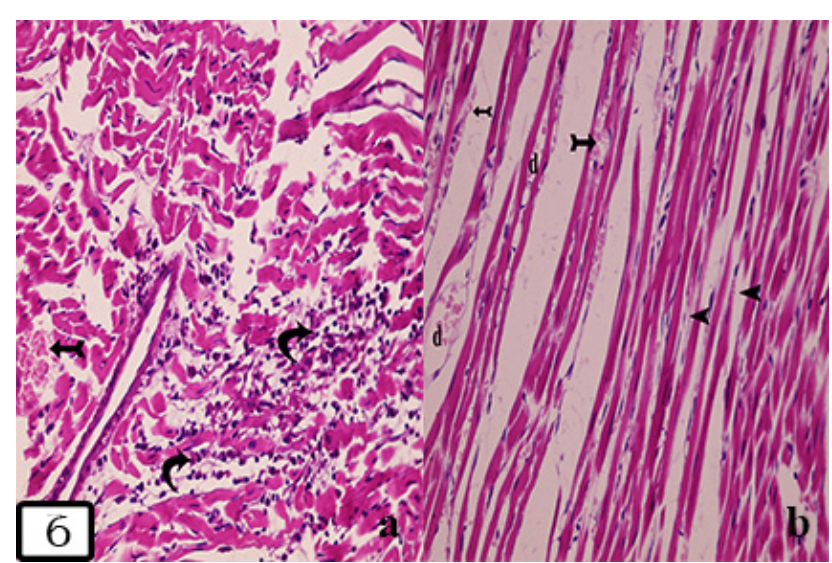

Fig 6: A photomicrograph of the cardiac muscle sections of group III showing (a)Marked cellular infiltration (curved arrow), with extravasated blood in (aandb) (bifid arrows) and areas of discontinuation of the cardiomyocytes in b (arrow head) (b)Dilated blood vessels (d) (HandE $\mathrm{X} 400)$.

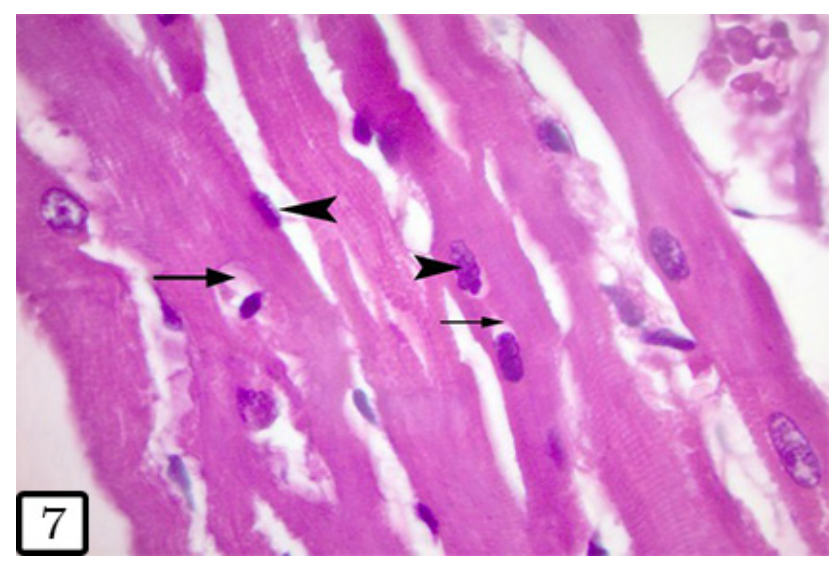

Fig 7: A photomicrograph of the cardiac muscle sections of group III showing irregular dark peripherally located nuclei (arrow head) and pale region at one side of the nuclei(arrow) (HandE X1000).

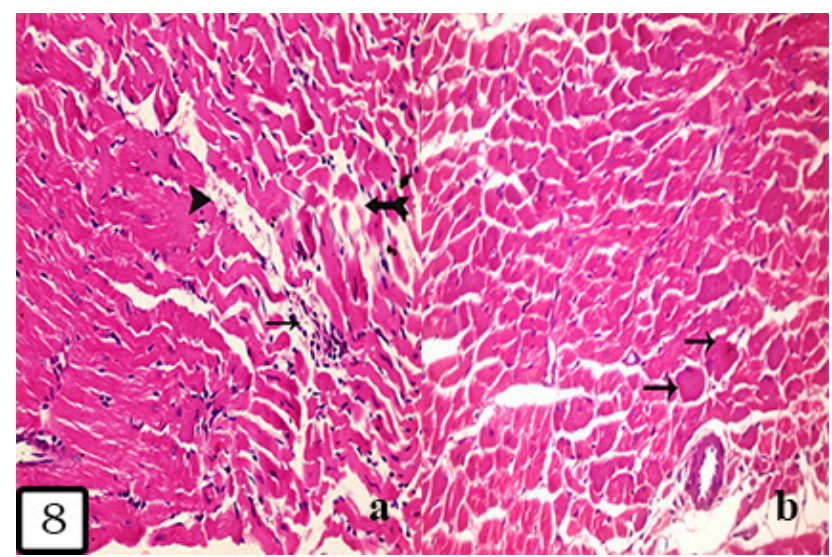

Fig 8: A photomicrograph of the cardiac muscle sections of group IV showing apparently normal cardiac muscle fibers(a)Little cellular infiltration (arrow), dilated blood vessels (arrow head) and area of muscle fiber discontinuation (bifid arrow). (b)Few large cardiomyocytes with deeply acidophilic sarcoplasm (thick arrow) (HandE X400).

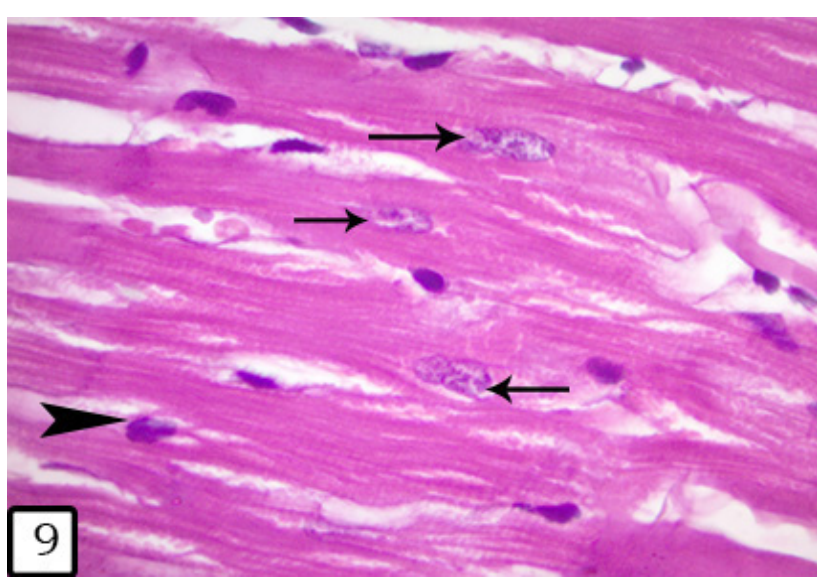

Fig 9: A photomicrograph of the cardiac muscle sections of group IV showing cardiac myocytes with central vesicular nuclei (arrow). Dark peripheral nuclei were also observed (arrow head) (HandE X1000).

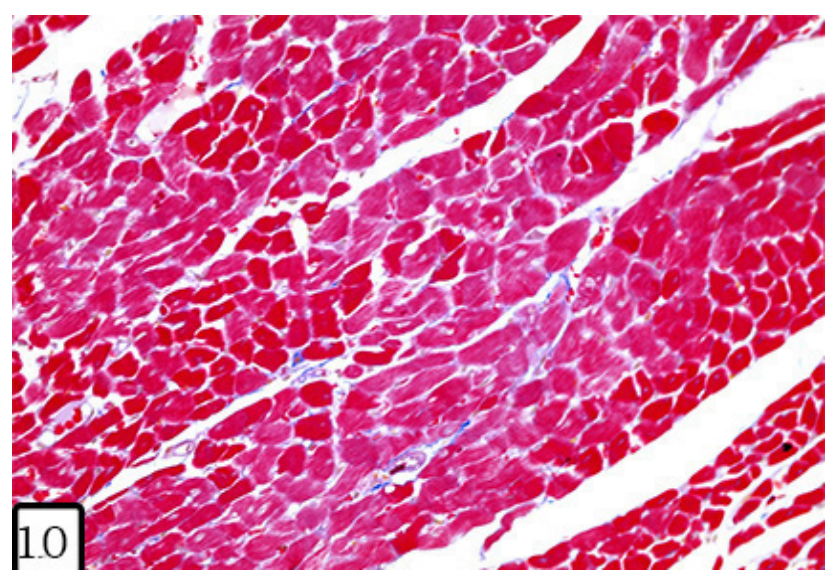

Fig 10: A photomicrograph of the cardiac muscle sections of control group showing little collagen fibers between the cardiac muscle fibers (Mallory trichrome X400).

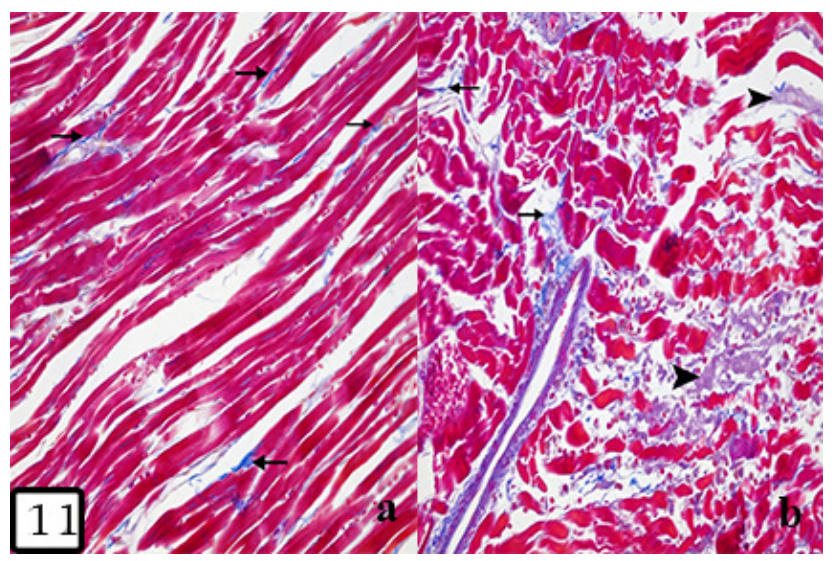

Fig 11: A photomicrograph of the cardiac muscle sections of group III showing increased collagen fibers deposition (a) In between the cardiac muscle fibers (arrow). (b) At the site of degenerated cardiac muscle fibers (arrow head) (Mallory trichrome X400). 


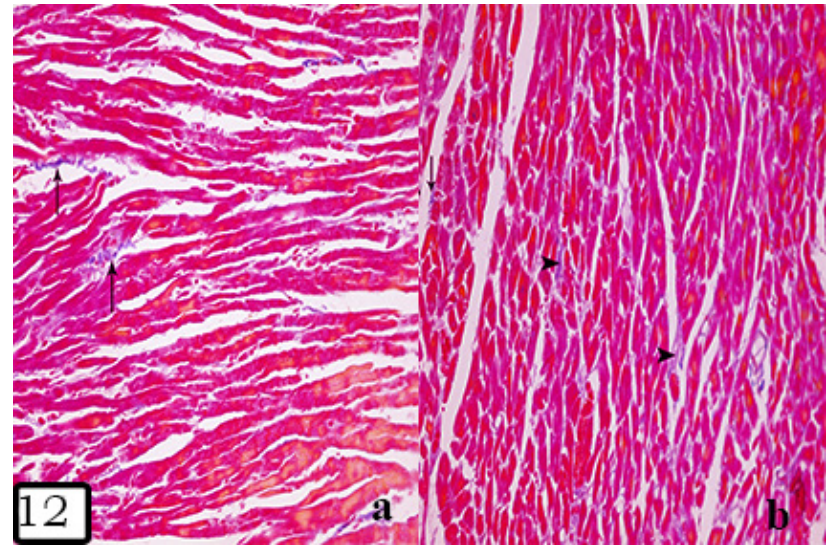

Fig 12: A photomicrograph of the cardiac muscle sections of group IV showing little collagen fibers (aandb) In between the cardiac muscle fibers (arrow) (b) At areas of discontinuation of the cardiac muscle fibers (arrow head) (Mallory trichrome X400).

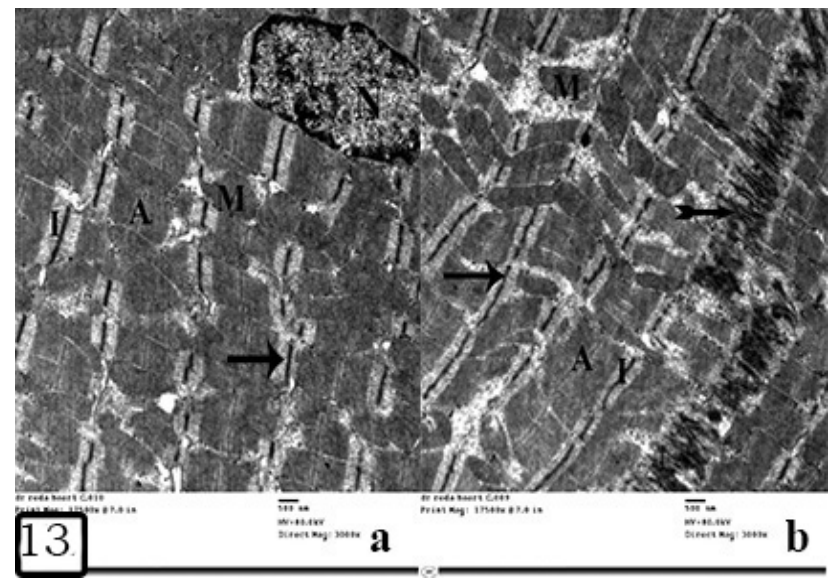

Fig 13: An electron micrograph of ultrathin section of the cardiac muscle of the control group showing sarcomeres, each extended between two successive $\mathrm{Z}$ lines (arrow) with apparent dark (A) band and light (I) bands. Mitochondria (M) arranged in rows in between the myofibrils. Note (a)Single euchromatic nucleus (N)(b)Intercalated disk (bifid arrow).

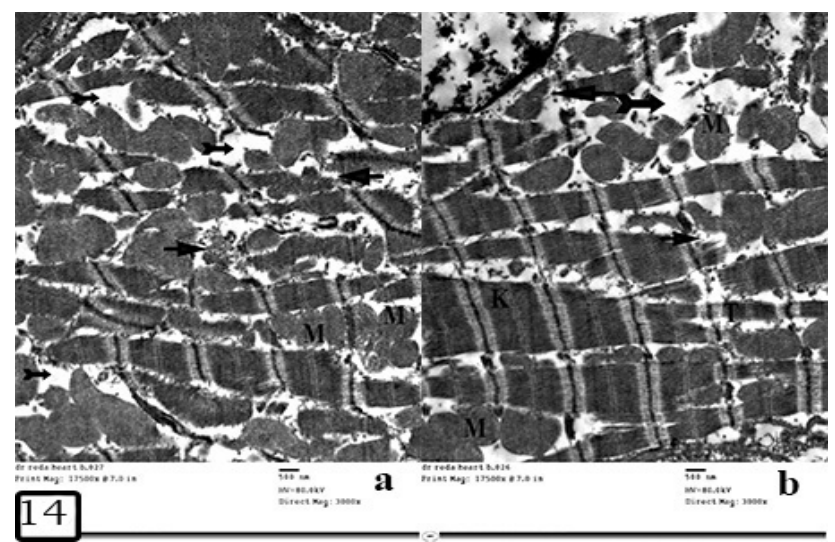

Fig 14: An electron micrograph of ultrathin section of the cardiac muscle of group III showing (aandb)disrupted sarcomeres, lysis and fragmentation of the myofibrils(arrow) as well as areas of cytoplasmic rarefaction (bifid arrow).Mitochondria of variable size and shape (M) were observed. (b) Some myofibrils were thin $(\mathrm{T})$ while others were thick $(\mathrm{K})$.

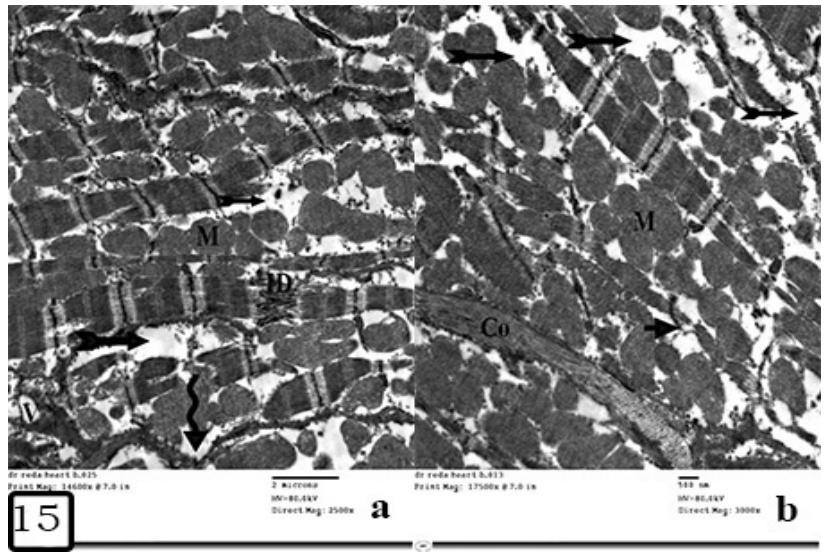

Fig 15: An electron micrograph of ultrathin section of the cardiac muscle of group III showing irregular sarcolemma (zigzag arrow), interrupted intercalated disk (ID) and small vacuoles (V). Areas of cytoplasmic rarefaction (bifid arrow) and variable size and shape of mitochondria (M) were detected (aandb). Notice (b) Presence of collagen fibers (CO)in between the cardiomyocytes.

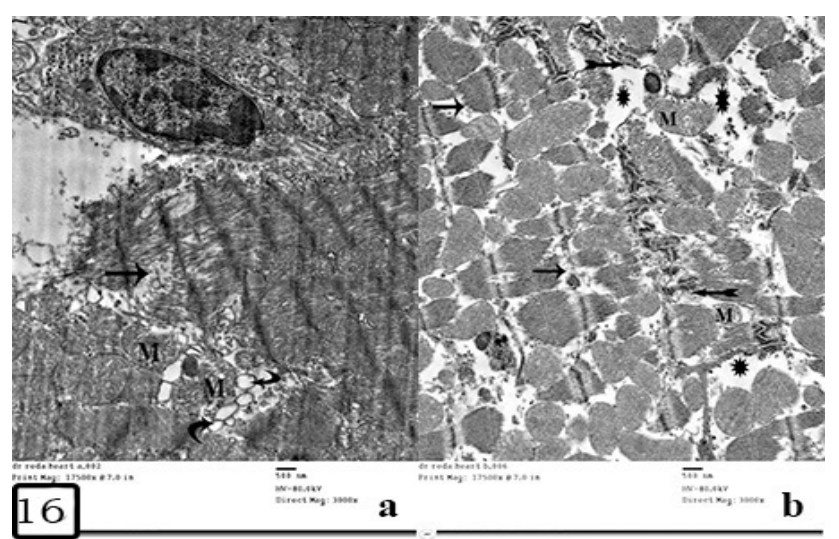

Fig 16: An electron micrograph of ultrathin section of the cardiac muscle of group III showing (a)Dilated sarcoplasmic reticulum (curved arrow), lysis of the myofibrils (arrow) and partially damaged mitochondria (M) in (aandb).(b)Complete loss of myofibrils (star) and interrupted intercalated disk (bifid arrow)were observed.

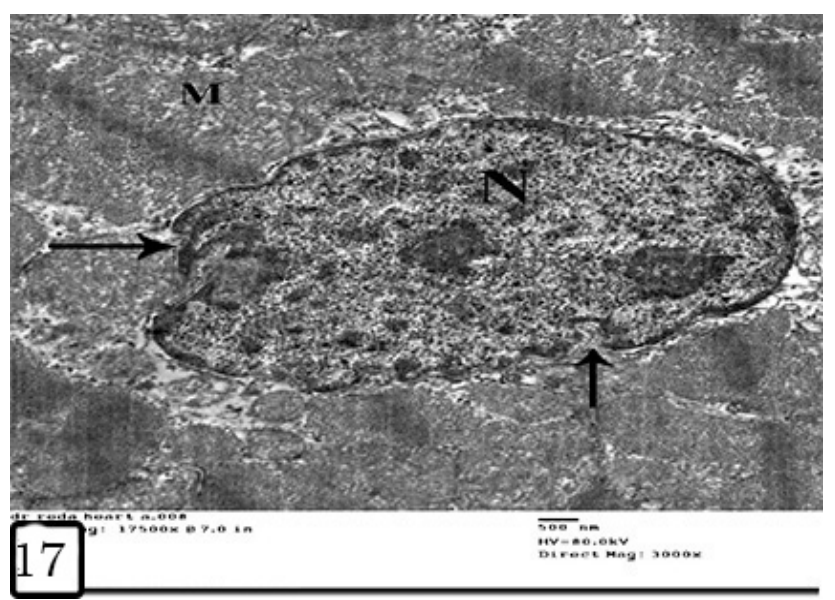

Fig 17: An electron micrograph of ultrathin section of the cardiac muscle of group III showing irregular indented (arrow) nucleus (N) and partially damaged mitochondria $(\mathrm{M})$ 


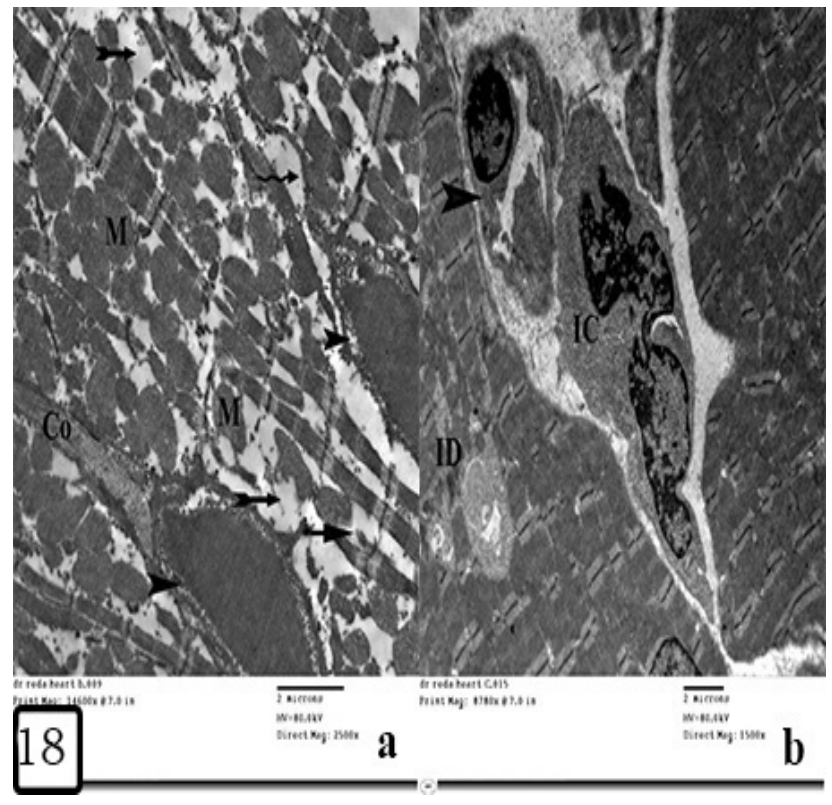

Fig 18: An electron micrograph of ultrathin section of the cardiac muscle of group III showing (a) Irregular sarcolemma (zigzag arrow), areas of cytoplasmic rarefaction (bifid arrow) and lysis of the myofibrils (arrow). Notice presence of mitochondria of variable size and shape (M) and collagen fibers (CO). Blood capillaries (arrow head) (aandb), inflammatory cells (IC) and interrupted intercalated disk (ID) were observed in between cardiac myocytes (b).

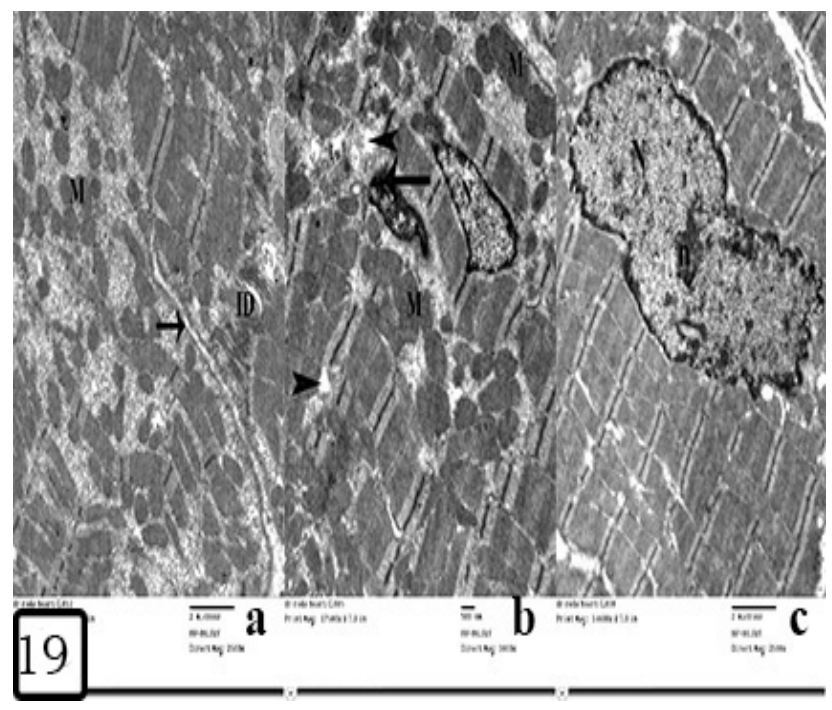

Fig 19: An electron micrograph of ultrathin section of the cardiac muscle of group IV showing apparently normal cardiomyocytes with regularly arranged sarcomeres(a)Apparently normal intercalated disk (ID), sarcolemma (arrow) and aggregated mitochondria (M).(b)Variable shaped mitochondria in between the myofibrils (M), few sarcoplasmic vacuoles (arrow head) and irregular small nucleus (arrow) were detected. Notice presence of another euchromatic nucleus (N).(c)Apparently normal euchromatic nucleus $(\mathrm{N})$ with prominent nucleolus (n).

\section{DISCUSSION}

Liver fibrosis is a major medical problem associated with high morbidity and mortality ${ }^{[14]}$. Advanced fibrosis can result into development of cirrhosis, liver failure, portal hypertension and hepatocellular carcinoma ${ }^{[15]}$. Cirrhotic cardiomyopathy is a chronic dysfunction associated with impaired cardiac contractility that occurs in cirrhotic patients with no history of cardiac diseases ${ }^{[16]}$.

In this study we used CCL4 for induction of liver fibrosis, because it is the most commonly used model for induction of liver fibrosis ${ }^{[6]}$.

In the present study, we examined effects of experimentally (CCL4) induced liver fibrosis on the histological structure of the cardiac muscle of adult male albino rats and the possible protective effect of propolis. From our results, it could be demonstrated that liver fibrosis led to changes in the normal histological structure of the cardiac muscle. The cardiac muscle obtained from group III which received CCL4 showed wide separation of the cardiomyocytes with presence of fat cells and connective tissue cells as well as homogenous acidophilic substance in between the myocytes. Cellular infiltration, blood capillaries dilatation and extravasation of red blood cells were also observed. Some cardiomyocytes revealed dark irregular peripherally located nuclei with presence of pale area at one side of them. Apparent increase in collagen fibers deposition was also noticed in between the muscle fibers as well as at areas of damaged fibers. These findings were also documented with the electron microscope. In addition, mitochondria appeared variable in size and shape with partial degeneration. Sarcoplasmic rarefaction dilated sarcoplasmic reticulum and interrupted intercalated disks were also reported.

Due to the close relation between the cardiovascular and autonomic nervous systems (ANS), the abnormal ANS function in cirrhotic patients could result in several cardiac and vascular alterations ${ }^{[17]}$. It was documented that liver cirrhosis causes hyperdynamic circulation with increased cardiac output and decreased peripheral vascular resistance. The increase in the cardiac output stimulates the sympathetic nervous system. This sympathetic hyperactivity causes direct damage of the cardiomyocytes and also causes an increase in levels of the inflammatory cytokines such as interleukins (IL-8, IL-6 and IL-1b), tumor necrosis factor alpha (TNF- $\alpha$ ) and transforming growth factor beta (TGF- $\beta$ ). Both IL- $1 \mathrm{~b}$ and TNF- $\alpha$ stimulate production of nitric oxide (NO) which is a strong inflammatory mediator ${ }^{[16]}$. The excessive production of nitric oxide and endothelin may be the cause of cardiomyocyte lesion ${ }^{[18]}$. Cellular infiltration and vascular changes in the present work could also caused by the increased levels of NO. In addition, the TGF- $\beta$ stimulates the mitogen-activated protein kinases (MAPK) that promote cardiomyocytes apoptotic cell death. Apoptosis of the cardiomyocytes in cirrhotic patients can also be caused by abnormalities in the $\mathrm{Na}+/ \mathrm{Ca}+2$ exchanger which is responsible for keeping balance between $\mathrm{Ca}+2$ influx and efflux through the cell membrane and so maintaining the intracellular steady state free $\mathrm{Ca}+2$ concentration. Abnormalities in the $\mathrm{Ca}+2$ level could also cause disturbance in the cell cytoskeleton and this could explain the peripheral location of the nuclei reported in the present study ${ }^{[16]}$ 
Our results were in accordance with some authors ${ }^{[19]}$ who found increased deposition of collagen fibers and disarrangement of the cardiomyocytes with increased intercellular spaces. They demonstrated that when the liver is damaged kupffer cells produce transforming growth factor (TGF- $\beta$ ) which is a multifunctional cytokines that secreted by many cells like white blood cells and macrophage. It affects different types of cells including endothelial, epithelial, immune cells and stem cells. TGF-B promotes deposition of extracellular matrix and formation of interstitial fibrosis through the TGF- $\beta$ signaling pathway. TGF-B modulates fibroblast phenotype, increases fibronectin synthesis and regulates collagen deposition in the infarction.

As regards the damaged and abnormally shaped and sized mitochondria detected in this work, other researchers $^{[20]}$ explained it to be due to increased permeability of the inner and outer mitochondrial membranes to solutes, protons and metabolites, a process that could lead to death of the mitochondria. It was also reported that mitochondrial injury could be due to some toxins that accumulate in the mitochondria and interfere with oxidative phosphorylation or electron transport leading to ATP depletion and mitochondrialswelling ${ }^{[21]}$. On the other hand, subsarcolemmal accumulation of the mitochondria detected in propolis treated group could be considered as a sign of regeneration and an attempt of the cell to compensate for the respiratory chain defect ${ }^{[22]}$.

It was documented that loss of the cardiomyocytes by either apoptosis or necrosis is a key feature in cardiomyopathy ${ }^{[23]}$. Damage of the myofibrils could be explained according to Elwan et al., ${ }^{[24]}$ to be a consequence of mitochondrial dysfunction that leads to loss of ATP production as well as imbalance of calcium uptake. Sarcoplasmic reticulum vacuolation could be explained according to other researchers to be the result of expansion of different cytoplasmic membranous organelles secondary to redistribution of intracellular water and electrolytes ${ }^{[25]}$. Moreover, Cotran et al., ${ }^{[26]}$ have explained the sarcoplasmic vacuolation to be due to depletion of ATP and disturbance of the sodium potassium ion transport system through the cell membranes.

Some authors ${ }^{[27]}$ have illustrated that chronic stress caused dilatation and congestion of the myocardial blood vessels through enhancing the sympathetic activity. They have also reported that in cardiomyopathy, mononuclear cellular infiltration occurred close to areas of degenerated cardiac muscle cells. Later, these degenerated cells became replaced by fibrous and adipose tissue cells. The cellular infiltration could also be explained according to Stevens et al., ${ }^{[28]}$ to be due to release of certain mediators after degeneration of the myocytes that attract the inflammatory cells. The extravasated red blood cells observed in the current study could be explained according to Durmus Altun et al., ${ }^{[29]}$ to be secondary to tissue hypoxia which causes an increase in the capillary permeability.
One common finding in this work was interrupted intercalated disc (ICD) that have been documented in other researches ${ }^{[30]}$ and was explained by mitochondrial damage that caused depletion of ATP production and activation of phospholipase enzyme leading to breakdown of the phospholipids. This resulted in abnormality of lipid peroxidation of the sarcolemma and internal membranes leading to loss of the control of ions permeability and a subsequent abnormality in the membrane structure which could explain the irregular sarcolemma found in the present study ${ }^{[31]}$. Koeppen et al., ${ }^{[32]}$ have proposed another possible explanation of ICD abnormality to be due to changes in the molecular proteins of the junctions present within the ICD as N-cadherin, vinculin and desmosomal protein desmoglein 2 as well as abnormal distribution of the connexin 43 protein within the gap junction. These changes may be a result of autoantibody attacks these molecular proteins. These molecular deviations might play a rule in ICD changes ${ }^{[33]}$.

Treatment with propolis in group IV attenuated the cardiomyopathy and improved the previously mentioned histopathological changes observed in the cardiac muscle of group III signifying its cardio-protective effect in the current study. These results were in accordance with the results of other researchers who proved the cardioprotective effect of propolis against doxorubicin and aluminum chloride respectively ${ }^{[34,35]}$. It was documented that the anti-inflammatory activity of propolis is mediated by inhibiting phospholipase A2, lipoxygenase (5,12, and15), cyclooxygenase (COX-2) and nitric oxide synthase (NOS). This decreases production of prostaglandin E2 (PGE2), thromboxane A2, leukotriene B4 and nitric oxide (NO) which all have a role in development of inflammatory reactions ${ }^{[36]}$. In addition, propolis inhibits mRNA IL 1B expression thus decreasing IL 1B synthesis. In their study on diabetic rats, Fuliang et al., ${ }^{[37]}$ have proved that propolis has anti-inflammatory properties by decreasing nitric oxide (NO) levels through decreasing levels and activity of nitric oxide synthase enzyme(NOS).

Other authors have related the antioxidant capacity of propolis to be due to its content of flavonoids which are powerful antioxidants through scavenging the free radicals. In addition, propolis was reported to be capable of reducing cellular $\mathrm{H}_{2} \mathrm{O}_{2}$ and $\mathrm{NO}$ levels which play a role in cellular death in certain conditions such as cardiovascular diseases. They have also added that propolis antioxidant activity may be contributed to other components such as caffeic acid phenethyl ester (CAPE) which blocks production of reactive oxygen species (ROS) in many systems ${ }^{[38]}$. In addition, it has been documented that CAPE protected the cardiac muscle against oxidative stress in a model of hyperthyroidism ${ }^{[39]}$. CAPE also showed a cardio-protective effect against myocardial ischemia via its antioxidant effect and via decreasing activity of both xanthine oxidase (XO) and adenosine deaminase (ADA) $)^{[40]}$.

To our knowledge, this is the first study investigating the 
effect of propolis on the cardiac muscle in a liver fibrosis model. In our study, propolis administration significantly decreased the cardiac muscle histological changes that occurred secondary to the liver fibrosis. Therefore, we suggest that propolis may have a possible cardioprotective effect in cirrhotic cardiomyopathy.

\section{CONCLUSION}

In the current study, we demonstrated the protective effect of propolis on the cardiac muscle against the changes caused secondary to liver fibrosis. So, we may suggest that propolis could be a potential promising agent for treatment of cirrhotic cardiomyopathy.

\section{RECOMMENDATIONS}

We recommend prescription of propolis for patient suffering from chronic liver disease to protect their hearts. We also recommend further experimental studies with the use of different doses of propolis for different periods. Clinical trials should be considered.

\section{ACKNOWLEDGEMENTS}

The authors would like to thank Dr. Naglaa Ahmed Bayomi, Professor of Histology, Faculty of Medicine, Tanta University, for her help and support.

\section{CONFLICTS OF INTEREST}

There is no conflict of interest to declare.

\section{REFERENCES}

1. Møller, S. and Bendtsen, F. (2015): Cirrhotic multiorgan syndrome. Digestive Diseases and Sciences. 60(11):3209-3225.

2. Wang, N., Xu, Q., Tan, H.Y., Hong, M., Li, S., Yuen, M. and Feng, Y. (2016): Berberine inhibition of fibrogenesis in a rat model of liver fibrosis and in hepatic stellate cells. Evidence-Based Complementary and Alternative Medicine.(8762345):P11.

3. Tabet, E., Genet, V., Tiaho, F., Lucas-Clerc, C., Moana, G., Piquet-pellorce, C. and Samson, M. (2016): Chlordecone potentiates hepatic fibrosis in chronic liverinjury induced by carbon tetrachloride in mice. Toxicology Letters. 25(255):1-10.

4. Fede, G., Privitera, G., Tomaselli, T., Spadaro, L., and Purrello, F. (2015):Cardiovascular dysfunction in patients with liver cirrhosis. Annals of Gastroenterology. 28(1): 31-40.

5. Shaker ME, Houssen ME, Abo-Hashem EM, and Ibrahim TM(2009): Comparison of vitamin E, L-carnitine and melatonin in ameliorating carbon tetrachloride and diabetes induced hepatic oxidative stress. J Physiol Biochem; 65(3):225-33

6. Scholten, D., Trebicka, J., Liedtke, C. and Weiskirchen, R. (2015): The carbon tetrachloride model in mice. Laboratory animals.49 (S1): 4-11.
7. Domitrovic, R., Jakovac, H., Tomac, J. and Sain, I. (2009): Liver fibrosis in mice induced by carbon tetrachloride and its reversion by luteolin. Toxicology and Applied Pharmacology. 241:311-321.

8. Ahmed, R., Tanvir, E.M., Hossen, M.S., Afroz, R., Ahmmed, I., Rumpa, N., Paul, S., Gan, S.H., Sulaiman, S.A. and Khalil, M.I. (2017): Antioxidant Properties and Cardioprotective mechanism of Malaysian propolis in rats. Evidence-Based Complementary and Alternative Medicine (5370545): 11 pages.

9. Hassan, A., Elhendy, R., Al-Yamani, M.A.S. and Sayrafi, M.A. (2017): Effect of Saudi propolis on hepatitis male rats. Journal of Nutrition and Food Sciences.7 (4):5 pages.

10. Daleprane, J.B. and Abdalla, D.S. (2013): L -carnitine and melatonin reverse $\mathrm{CCl} 4$ induced liver fibrosis in rats (histological and histochemical studies). Evidence-Based Complementary and Alternative Medicine (175135): 8 pages.

11. Ying $\mathrm{Qu}$, Lei Zong, Mingyi Xu, Yuwei Dong,

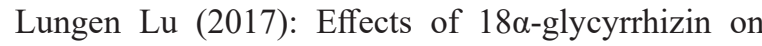
TGF- $\beta 1 /$ Smad signaling pathway in rats with carbon tetrachloride-induced liver fibrosis Int $\mathrm{J}$ Clin Exp Pathol.; 8(2): 1292-1301.

12. Kilicoglu S.S., Kilicoglu B., Erdemli E. (2008): Ultrastructural view of colon anastomosis under propolis effect by transmission electron microscopy. World Journal of Gastroenterology. 14: 4763-4770.

13. Kuo J. (2007): Electron Microscopy, Methods and Protocols,2nd edition. Humana Press Inc. Totowa, New Jersey. p.369.

14. Wang, G., Li, Z., Li, H., Li, L., Li, J., and Yu, C. (2016): Metabolic profile changes of CCl4-liver fibrosis and inhibitory effects of jiaqiganxiangranule. Molecules. (21): 19 pages.

15. Huang, X., Wang, X., Lv, Y., Xu, L., Lin, J., and Diao, Y. (2014): Protection effect of kallistatin on carbon tetrachloride-induced liver fibrosis in rats via antioxidative stress. PLOS ONE. 9(2): e88498.

16. Chayanupatkul, M., and Liangpunsakul, S. (2014): Cirrhotic cardiomyopathy: review of pathophysiology and treatment. Hepatology International. 8(3): 308-315.

17. Elias Tsiompanidis, Spyros I Siakavellas, Tentolouris, Ioanna Eleftheriadou, Stamatia Chorepsima, Anastasios Manolakis, Konstantinos Oikonomou, and Nikolaos Tentolouris(2018): Liver cirrhosiseffect on QT interval and cardiac autonomic nervous system activity.World Journal of Gastrointestinal Oncolgy.9(1): 28-36.

18. Mocarzel, L.O.C., Rossi, M.M., Miliosse, B.de M., Lanzieri, P.G.,and Gismondi, R.A. (2017): Cirrhotic 
Cardiomyopathy: A New Clinical Phenotype. Arquivos Brasileiros de Cardiologia. 108(6):564-568.

19. Yang, C., Ting, W., Day, C., Ju, D., Yeh, Y., Chung, L., Tsai, F., Tsai, C., Tsai, Y. and Huang, C. (2014): SHSST cyclodextrin complex prevents the fibrosis effect onCCl4-induced cirrhotic cardiomyopathy in rats through TGF- $\beta$ pathway inhibition effects. International Journal of Molecular Sciences.(15): 8037-8048.

20. Belizário, J.E., Alves, J., Occhiucci, J.M., GarayMalpartida, M. andSesso, A.(2007): A mechanistic view of mitochondrial death decision pores. Brazilian Journal of Medical and Biological Research. 40(8):1011-1024.

21. Cheville, N.F. (2009): Mitochondria, Ch: 8, in, Ultrastructural pathology: The comparative cellular bases of disease.2nd edition, Wiley Blackwell.P:181.

22. Cullen, M.J., Johnson, M.A., and Mastalgia, F.L. (2001): Pathological reactions of skeletal muscle pathology. 2nd edition. Churchill Livingstone, Edinburgh, London, P: 123.

23. Saidu, Y., Usman, M.J., Isa, S.A., Isezuo, S.A., Bilbis, L.S., Sahabi, S.M., Bello, A. and Muhammad, S.A. (2017): Biochemical and histological changes in the heart of post-partum rats exposed to Natron. Indian Heart Journal.Article in press.

24. Elwan, W.M.,Kassab, A.A. and Ibrahim, M.A.A. (2016): The possible role of berberine in ameliorating doxorubicin-induced cardiomyopathy in adult male albino rat: a histological and immunohistochemical study. The Egyptian Journal of Histology.(39): 228-240.

25. Balli, E.,Mete, U.O., Tuli, A., Top, O. and Kaya, M. (2004): Effect of melatonin on the cardiotoxicity of doxorubicin. Histology and Histopathology(19): 1101-1108.

26. Kumar, V., Abbas, K and Aster, J. (2015): Cellular pathology I: Cellular Responses to Stress and Toxic Insults: Adaptation, Injury, and Death, Ch: 1, in Robbins Pathologic Basis of Disease, 9th edition, W.B. Saunders Company, Philadelphia, London, Toronto, Montreal, Sydney, Tokyo. P:3.

27. Demirci, T. and Sahin, E. (2017): Heart and stress: A morphometric and light microscopic study in a rat model. Averroes European Medical Journal.4(2): 9 pages.

28. Stevens, A., Lowe, J. and Scott, I. (2007): Tissue response to damage, $\mathrm{Ch}: 4$, in Core Pathology,3rd edition, Mosby, St. Louis, Baltimore, Boston, Chicago, New York, Sydney, Tokyo, Toronto. P: 35.

29. Durmus-Altun, G., Altun, A., Aktas, R.G., Salihoglu, Y.S., and Yigitbasi, N.O. (2005): Use of iodine-123 metaiodobenzyl guanidine scintigraphy for the detection of amiodarone induced pulmonary toxicity in a rabbit model: a comparative study with technetium- $99 \mathrm{~m}$ diethyltriaminepenta acetic acid radioaerosol scintigraphy. Annals of Nuclear Medicine. 19(3):217-224.

30. Pankuweit S, Richter A, Ruppert V, Maisch B(2009): Classification of cardiomyopathies and indication for endomyocardial biopsy revisited. Herz. ; 34(1):55-62.

31. Soliman, G.M. and Tawfik, S.M.(2014): Histological and immunohistochemical study on the effect of aflatoxin B1 on the left ventricular muscle of adult male rabbit with reference to the protective role of melatonin The Egyptian Journal of Histology. 37:655-666.

32. Koeppen, A.H., Becker, A.B., Feustel, P.J., Gelman, B.B.and Mazurkiewicz, J.E. (2016): The significance of intercalated discs in the pathogenesis of Friedreich cardiomyopathy. Journal of the Neurological Sciences.15(367):171-176.

33. Andrew P. Kowalczyk and Kathleen J. Green (2013): Structure, Function and Regulation of Desmosomes. Prog Mol Biol Transl Sci; 116: 95-118.

34. Alyane, M., Kebsa, L.B.W., Boussenane, H.N., Rouibah, H.and Lahouel, M. (2008): Cardioprotective effects and mechanism of action of polyphenols extracted from propolis against doxorubicin toxicity. Pakistan Journal of Pharmaceutical Sciences.21(3): 201-209.

35. Alqayim, M.A.J (2015): Propolis cardio protective role from the impact of aluminum chloride in female rabbits. Basrah Journal of Veterinary research.14(2): 136-149.

36. Korek-Gorecka, A., Rzepecka-Stojko, A., Gorecki, M., Stojko, J., Sosada, M.and Swierczek-Zieba, G. (2014): Structure and Antioxidant Activity of Polyphenols Derived from propolis. Molecules.(19): 78-101.

37. Fuliang, H.U., Hepburn, H.R., Xuan, H., Chen, M., Daya, S. and Radloff, S.E. (2005): Effects of propolis on blood glucose, blood lipid and free radicals in rats with diabetis mellitus. Pharmacological research.51 (2): 147-152.

38. Daleprane, J.B. and Abdalla, D.S. (2013): Emerging roles of propolis: antioxidant, cardioprotective, and antiangiogenic actions. Evidence-Based Complementary and Alternative Medicine. (175135): 8 pages.

39. Mohamadin, A.M., Hammad, L.N., El-Bab, M.F. and Abdel Gawad, H.S. (2007): Attenuation of oxidative stress in plasma and tissues and tissues of rats with experimentally induced hyperthyroidism by caffeic acid phenylethyl ester. Basic and Clinical Pharmacology and Toxicology.100 (2):84-90.

40. Ince, H., Kandemir, E., Bagci, C., Gulec, M. and Akyol, O. (2006): The effect of caffeic acid phenethyl ester on short-term acute myocardial ischemia.Medical Science Monitor.12 (5): 187-193. 


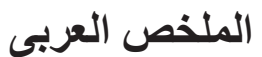

\section{التأثير الوقائي المحتمل لثمع العل على اصابة عضلة القلب الناجمة عن تليف الكبد في ذكور

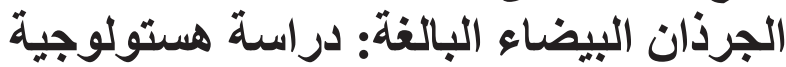

\author{
رضا حسن البقرى و منى تيسبر صادق

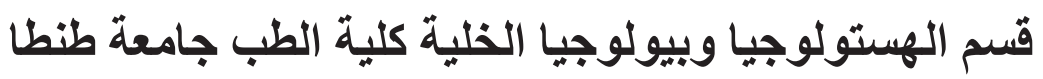

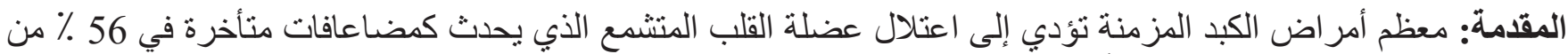

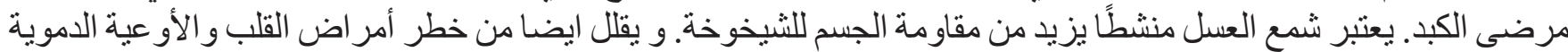
وتصلب الثر ايين. الهاف من العمل: هو در اسة الدور الوقائي المحتمل لثمع العسل على التغير ات النسيجية التي حدثت في عضلة القلب كنتيجة ثانوية لتليف الكبد.

المواد و الطرق: تم تقسيم 40من ذكور الجرذان السليمة بشكل عشو ائى إلى 4 مجمو عات:(المجمو عة الأولى) المجمو عة الضابطة،

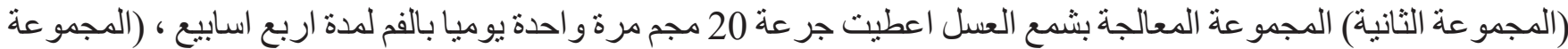

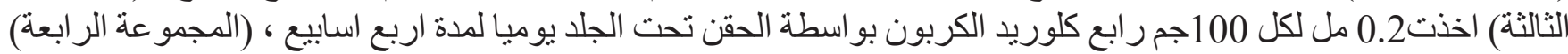

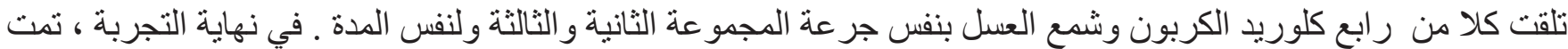
التضحية بجميع الجرذان وتم الحصول على عضلة القلب وتحضير ها من أجل الفحص بالمجهر الضونئى والإلكترونى.

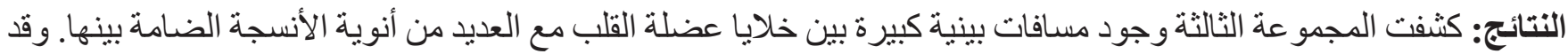
لوحظت فجو ات فى السيتو بلازم و تحلل بالالياف. وجد تمدد بالاو عية الدموية و العديد من الخلايا ـ تم الكشف عن زيادة الكادة الألياف الكو لاجينية بو اسطة صبغة مالوري. وشملت التغييرات التركيب الدقيق عدم، انتظام الوحدة البنائية للعضلة وتقطع في ألقائ أقراص

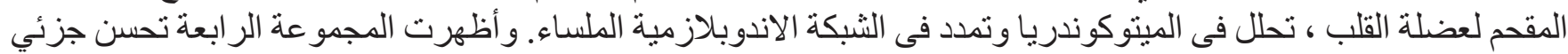
فى الترتيب المنتظ للألياف القلبية. الاستنتاجات: استخدام شعع العسل ادى الى تحسن جزئي فى التغير ات النسيجية التي حدثت في عضلة القلب نتيجة لتليف الكبد. 